\title{
STABILISASI SISTEM KONTROL LINIER INVARIANT WAKTU DENGAN MENGGUNAKAN METODE ACKERMANN
}

\author{
DIAN PUSPITA BEY \\ Program Studi Matematika, \\ Fakultas Matematika dan Ilmu Pengetahuan Alam, Universitas Andalas, \\ Kampus UNAND Limau Manis Padang, Indonesia, \\ dianpuspitabey@yahoo.com
}

\begin{abstract}
Abstrak. Dalam penelitian ini dikaji proses stabilisasi suatu sistem kontrol linier invariant waktu dengan menggunakan metode Ackermann. Kajian ini diaplikasikan pada sistem pendulm terbalik yang bersifat tidak stabil, namun dapat distabilkan jika terdapat kontrol feedback $\mathbf{u}=-K \mathbf{x}$ sedemikian sehingga sistem loop tertutup $\dot{\mathbf{x}}=(A-B K) \mathbf{x}$ adalah stabil dengan nilai eigen dari matriks $A-B K$ dapat ditempatkan sesuai keinginan. Dengan ilustrasi yang diberikan, diperoleh matriks feedback $K$ yang membuat sistem pendulum terbalik menjadi stabil.
\end{abstract}

Kata Kunci: Metode Ackermann, kestabilan sistem, pendulum terbalik

\section{Pendahuluan}

Diberikan suatu sistem kontrol linier sebagai berikut:

$$
\begin{aligned}
& \dot{\mathbf{x}}=A \mathbf{x}+B \mathbf{u}, \quad \mathbf{x}(0)=\mathbf{x}_{0} \\
& \mathbf{y}=C \mathbf{x}
\end{aligned}
$$

di mana $A \in \mathbb{R}^{n \times n}, B \in \mathbb{R}^{n \times m}, C \in \mathbb{R}^{p \times n}, \mathbf{x}=\mathbf{x}(t) \in \mathbb{R}^{n}$ menyatakan variabel keadaan (variabel state), $\mathbf{u}=\mathbf{u}(t) \in \mathbb{R}^{m}$ menyatakan variabel kontrol (input), $\mathbf{y}=\mathbf{y}(t) \in \mathbb{R}^{p}$ menyatakan variabel output. Matriks $A, B$, dan $C$ tidak bergantung terhadap waktu, sehingga sistem disebut sistem kontrol linier invariant waktu.

Salah satu kajian utama sistem kontrol adalah kajian tentang kestabilan sistem tersebut. Kriteria untuk menentukan kestabilan sistem adalah nilai eigen matriks $A$, yaitu sistem dikatakan stabil jika bagian riil dari semua nilai eigen matriks $A$ adalah negatif [5]. Sistem dikatakan stabil, jika $t \rightarrow \infty$ mengakibatkan $\mathbf{x}(t) \rightarrow \mathbf{0}$.

Sistem dapat distabilkan jika terdapat kontrol feedback $\mathbf{u}=-K \mathbf{x}$ untuk suatu $K \in \mathbb{R}^{m \times n}$ sedemikian sehingga sistem loop tertutup $\dot{\mathbf{x}}=(A-B K) \mathbf{x}$ adalah stabil. $K$ adalah matriks feedback dan vektor $\mathbf{u}$ dikatakan kontrol yang menstabilkan sistem.

Selanjutnya, eksistensi $\mathbf{u}$ dapat ditentukan jika sistem terkontrol lengkap [5]. Pada paper ini, akan dibahas bagaimana bentuk matriks $K$ yang membuat sistem $\dot{\mathbf{x}}=(A-B K) \mathbf{x}$ stabil, tetapi nilai eigen dari matriks $A-B K$ dapat ditempatkan sesuai keinginan. Permasalahan seperti ini sering disebut sebagai masalah penempatan pole [5]. 


\section{Stabilisasi Sistem Kontrol Linier Invariant Waktu dengan Menggunakan Metode Ackermann}

Perhatikan kembali sistem kontrol linier (1.1) dan asumsikan bila sistem tersebut terkontrol lengkap dan terdapat suatu kontrol feedback $\mathbf{u}=-K \mathbf{x}$ untuk suatu $K$ sedemikian sehingga sistem loop tertutup

$$
\dot{\mathbf{x}}=(A-B K) \mathbf{x}
$$

adalah stabil.

Misalkan pole-pole loop tertutup yang diinginkan adalah $s=s_{1}, s=s_{2}, \ldots, s=$ $s_{n}$. Persamaan karakteristik dari matriks $A-B K$ adalah

$$
\begin{aligned}
|s I-\tilde{A}| & =\left(s-s_{1}\right)\left(s-s_{2}\right) \cdots\left(s-s_{n}\right) \\
& =s^{n}+\alpha_{1} s^{(n-1)}+\cdots+\alpha_{n-1} s+\alpha_{n}=0,
\end{aligned}
$$

untuk suatu skalar $\alpha_{i}, i=1,2, \cdots, n$, di mana $\tilde{A}=A-B K$. Berdasarkan teorema Cayley-Hamilton $\tilde{A}$, berlaku [5]

$$
\phi(\tilde{A})=\tilde{A}^{n}+\alpha_{1} \tilde{A}^{n-1}+\cdots+\alpha_{n-1} \tilde{A}+\alpha_{n} I=0 .
$$

Perhatikan identitas berikut:

$$
\begin{aligned}
I & =I \\
\tilde{A} & =A-B K \\
\tilde{A}^{2} & =\tilde{A} \tilde{A} \\
& =A^{2}-A B K-B K \tilde{A} \\
\tilde{A}^{3} & =\tilde{A}^{2} \tilde{A} \\
& =A^{3}-A^{2} B K-A B K \tilde{A}-B K \tilde{A}^{2} \\
& \vdots \\
\tilde{A}^{n} & =\tilde{A}^{n-1} \tilde{A} \\
& =A^{n}-A^{n-1} B K-A^{n-2} B K \tilde{A}-A^{n-3} B K \tilde{A}^{2}-\ldots-A B K \tilde{A}^{n-1}-B K \tilde{A}^{n}
\end{aligned}
$$

Akibatnya, persamaan (2.2) menjadi

$$
\begin{aligned}
0= & \alpha_{n} I+\alpha_{n-1} \tilde{A}+\alpha_{n-2} \tilde{A}^{2}+\ldots+\alpha_{1} \tilde{A}^{n-1}+\tilde{A}^{n} \\
& +A^{n}-A^{n-1} B K-A^{n-2} B K \tilde{A}-A^{n-3} B K \tilde{A}^{2} \\
& -\ldots-A B K \tilde{A}^{n-1}-B K \tilde{A}^{n} \\
= & \alpha_{n} I+\alpha_{n-1} A+\alpha_{n-2} A^{2}+\ldots+\alpha_{1} A^{n-1}+A^{n} \\
& -\alpha_{n-1} B K-\alpha_{n-2} A B K-\alpha_{n-2} B K \tilde{A} \\
& -\ldots-\alpha_{1} A^{n-2} B K-\alpha_{1} A^{n-3} B K \tilde{A} \\
& -\ldots-\alpha_{1} B K \tilde{A}^{n-1}-A^{n-1} B K-A^{n-2} B K \tilde{A}-A^{n-3} B K \tilde{A}^{2} \\
& -\ldots-A B K \tilde{A}^{n-1}+B K \tilde{A}^{n} \\
= & \phi(A)-\alpha_{n-1} B K-\alpha_{n-2} A B K-\alpha_{n-2} B K \tilde{A} \\
& -\ldots-\alpha_{1} A^{n-2} B K-\alpha_{1} A^{n-3} B K \tilde{A} \\
& -\ldots-\alpha_{1} B K \tilde{A}^{n-1}-A^{n-1} B K-A^{n-2} B K \tilde{A}-A^{n-3} B K \tilde{A}^{2} \\
& -\ldots-A B K \tilde{A}^{n-1}+B K \tilde{A}^{n} .
\end{aligned}
$$


Persamaan (2.3) dapat juga ditulis sebagai

$$
\phi(A)=\left[\begin{array}{ll}
B A B \cdots A^{n-1} B
\end{array}\right]\left[\begin{array}{c}
\alpha_{n-1} K+\alpha_{n-2} K \tilde{A}+\ldots+\alpha_{1} K \tilde{A}^{n-1}-K \tilde{A}^{n} \\
\alpha_{n-2} K+\ldots+K \tilde{A}^{n-1} \\
\vdots \\
K
\end{array}\right]
$$

Karena sistem terkontrol lengkap, invers dari matriks keterkontrolan

$$
\left[B A B \cdots A^{n-1} B\right]
$$

ada. Akibatnya

$$
\left[B A B \cdots A^{n-1} B\right]^{-1} \phi(A)=\left[\begin{array}{c}
\alpha_{n-1} K+\alpha_{n-2} K \tilde{A}+\ldots+\alpha_{1} K \tilde{A}^{n-1}-K \tilde{A}^{n} \\
\alpha_{n-2} K+\ldots+K \tilde{A}^{n-1} \\
\vdots \\
K
\end{array}\right] .
$$

Selanjutnya, dengan mengalikan kedua sisi persamaan diatas dengan

$$
\left[\begin{array}{llll}
0 & 0 & \cdots & 1
\end{array}\right] \text {, }
$$

diperoleh

$$
K=\left[\begin{array}{llll}
0 & 0 & \cdots & 1
\end{array}\right]\left[B A B \cdots A^{n-1} B\right]^{-1} \phi(A) .
$$

Persamaan (2.4) disebut sebagai metode Ackermann untuk menentukan matriks feedback $K[5]$.

\section{Aplikasi pada Sistem Pendulum Terbalik}

Aplikasi sistem kontrol loop tertutup dengan metode Ackermann diperlihatkan pada sistem pendulum terbalik (inverted pendulum). Pada sistem pendulum terbalik ini variabel-variabel yang bekerja adalah panjang bandul $(\ell)$, sudut simpangan $(\theta)$, massa kereta $(M)$, massa bandul $(m)$.

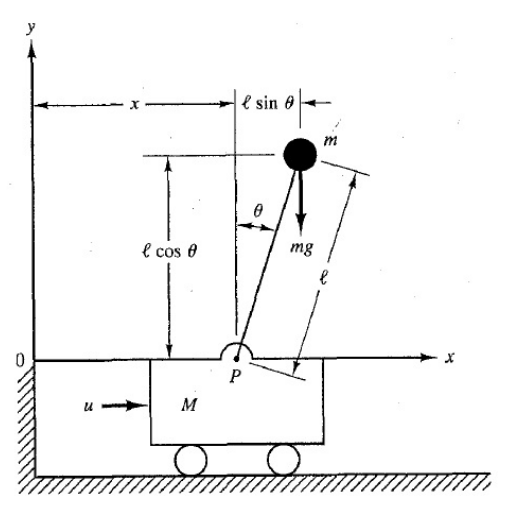

Gambar 3.1. Pendulum Terbalik 
Secara ilustratif, suatu pendulum terbalik seperti pada Gambar 3.1 terdiri dari dua bagian utama yaitu kereta beroda yang dapat bergerak ke arah kanan atau ke arah kiri dan pendulum dengan tangkainya yang dipasangkan dibagian tengah atas kereta yang dapat bergerak ke kiri dan ke kanan dengan membentuk sudut $\theta$ dengan arah vertikal. Asumsikan bahwa $\theta$ sangat kecil, $\sin \theta \doteqdot \theta, \cos \theta \doteqdot 1$, dan $\theta \dot{\theta^{2}} \doteqdot 0[4]$.

Sebagaimana terlihat pada Gambar 3.1, tujuan pengendalian adalah menjaga pendulum tersebut dalam posisi vertikal. Pendulum terbalik memiliki sifat yang tidak stabil dan memungkinkan pendulum tersebut jatuh ke segala arah. Tetapi dalam hal ini untuk penyederhanaan, gerak pendulum hanya dibatasi dalam satu dimensi sehingga pendulum terbalik tersebut bergerak pada dua arah derajat kebebasan yaitu gerak kereta ke kiri ( $y$ negatif) dan bergerak ke kanan ( $y$ positif), serta gerak pendulum ke kiri ( $\theta$ negatif) dan ke kanan ( $\theta$ positif) [6].

Definisikan koordinat $(x, y)$ pusat gravitasi massa sebagai $\left(x_{G}, y_{G}\right)$ [4]. Kemudian,

$$
\begin{aligned}
& x_{G}=x+\ell \sin \theta, \\
& y_{G}=\ell \cos \theta .
\end{aligned}
$$

Berdasarkan hukum Newton II gerakan searah sumbu $x$ menghasilkan

$$
M \frac{d^{2} x}{d t^{2}}+m \frac{d^{2} x_{G}}{d t^{2}}=u
$$

atau

$$
M \frac{d^{2} x}{d t^{2}}+m \frac{d^{2}}{d t^{2}}(x+\ell \sin \theta)=u .
$$

Persamaan (3.1) dapat ditulis sebagai:

$$
(M+m) \ddot{x}-m \ell(\sin \theta) \dot{\theta}^{2}+m \ell(\cos \theta) \ddot{\theta}=u .
$$

Perhatikan gerak rotasi massa $m$ disekitar titik $P$. Dengan menggunakan hukum Newton II untuk gerak rotasi diperoleh,

$$
m \frac{d^{2} x_{G}}{d t^{2}} \ell \cos \theta-m \frac{d^{2} y_{G}}{d t^{2}} \ell \sin \theta=m g \ell \sin \theta
$$

yang mana dapat disederhanakan menjadi:

$$
m\left[\ddot{x}-\ell(\sin \theta) \dot{\theta}^{2}+\ell(\cos \theta) \ddot{\theta}\right] \ell \cos \theta-m\left[-\ell(\cos \theta) \dot{\theta}^{2}-\ell(\sin \theta) \ddot{\theta}\right] \ell \sin \theta=m g \ell \sin \theta .
$$

Penyederhanaan lebih lanjut akan mengakibatkan

$$
m \ddot{x} \cos \theta+m \ell \ddot{\theta}=m g \sin \theta .
$$

Dengan mensubsitusikan $\sin \theta \doteqdot \theta, \cos \theta \doteqdot 1$, dan $\theta \dot{\theta^{2}} \doteqdot 0$, persamaan (3.2) dan (3.3) diperoleh:

$$
\begin{gathered}
(M+m) \ddot{x}+m \ell \ddot{\theta}=u, \\
m \ddot{x}+m \ell \ddot{\theta}=m g \theta .
\end{gathered}
$$


Persamaan (3.4) dan (3.5) merupakan model matematika dari sistem pendulum terbalik [4].

Persamaan sistem linier (3.4) dan (3.5) dapat dimodifikasi menjadi:

$$
\begin{gathered}
M \ell \ddot{\theta}=(M+m) g \theta-u \\
M \ddot{x}=u-m g \theta
\end{gathered}
$$

Definisikan variabel state $x_{1}, x_{2}, x_{3}$, dan $x_{4}$ dengan [5]:

$$
\begin{aligned}
& x_{1}=\theta \\
& x_{2}=\dot{\theta} \\
& x_{3}=x \\
& x_{4}=\dot{x}
\end{aligned}
$$

dan anggap $x_{3}$ sebagai output sistem, atau

$$
y=x_{3}=x .
$$

Dari definisi variabel state dan persamaan (3.6) dan (3.7), diperoleh:

$$
\begin{aligned}
\dot{x}_{1} & =x_{2} \\
\dot{x}_{2} & =\frac{M+m}{M \ell} g x_{1}-\frac{1}{M \ell} u \\
\dot{x}_{3} & =x_{4} \\
\dot{x}_{4} & =-\frac{m}{M} g x_{1}+\frac{1}{M} u,
\end{aligned}
$$

Persamaan (3.8) dan (3.9) secara simultan dapat ditulis menjadi

$$
\begin{gathered}
{\left[\begin{array}{l}
\dot{x}_{1} \\
\dot{x}_{2} \\
\dot{x}_{3} \\
\dot{x}_{4}
\end{array}\right]=\left[\begin{array}{cccc}
0 & 1 & 0 & 0 \\
\frac{M+m}{M \ell} g & 0 & 0 & 0 \\
0 & 0 & 0 & 1 \\
-\frac{m}{M} g & 0 & 0 & 0
\end{array}\right]\left[\begin{array}{l}
x_{1} \\
x_{2} \\
x_{3} \\
x_{4}
\end{array}\right]+\left[\begin{array}{c}
0 \\
-\frac{1}{M \ell} \\
0 \\
\frac{1}{M}
\end{array}\right] u} \\
y=\left[\begin{array}{llll}
0 & 0 & 1 & 0
\end{array}\right]\left[\begin{array}{l}
x_{1} \\
x_{2} \\
x_{3} \\
x_{4}
\end{array}\right]
\end{gathered}
$$

Persamaan (3.10) dan (3.11) adalah persamaan ruang keadaan (state space) dari sistem pendulum terbalik [4].

\section{Hasil dan Pembahasan}

Contoh berikut mengilustrasikan penentuan matriks feedback $K$ yang diambil dari [5] dengan $M=2 \mathrm{~kg}, m=0.5 \mathrm{~kg}, \ell=1 \mathrm{~m}$, maka

$$
A=\left[\begin{array}{cccc}
0 & 1 & 0 & 0 \\
12.25 & 0 & 0 & 0 \\
0 & 0 & 0 & 1 \\
-2.45 & 0 & 0 & 0
\end{array}\right], B=\left[\begin{array}{c}
0 \\
-0.5 \\
0 \\
0.5
\end{array}\right], C=\left[\begin{array}{llll}
0 & 0 & 1 & 0
\end{array}\right]
$$


Nilai eigen dari matriks $A$ adalah $\lambda_{1}=0, \lambda_{2}=0, \lambda_{3}=3.5$, dan $\lambda_{4}=-3.5$. Karena terdapat nilai eigen yang bernilai positif, maka pendulum terbalik tidak stabil (lihat Gambar 4.1).

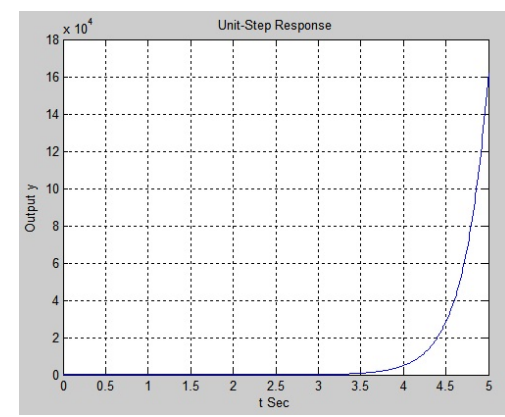

Gambar 4.1. Sistem Tak Stabil

Selanjutnya, karena

$$
\begin{aligned}
\operatorname{rank}\left[B A B A^{2} B A^{3} B\right] & =\operatorname{rank}\left[\begin{array}{cccc}
0 & -0.5 & 0 & -6.125 \\
-0.5 & 0 & -6.125 & 0 \\
0 & 0.5 & 0 & 1.225 \\
0.5 & 0 & 1.225 & 0
\end{array}\right] \\
& =4
\end{aligned}
$$

maka sistem terkontrol lengkap, sehingga sistem pendulum terbalik dapat distabilkan.

Misalkan pole-pole yang diinginkan adalah [5]

$$
\begin{aligned}
& s_{1}=-4+4 j \\
& s_{2}=-4-4 j \\
& s_{3}=-20 \\
& s_{4}=-20
\end{aligned}
$$

Persamaan karakteristik dari matriks $\tilde{A}$ adalah

$$
\begin{aligned}
|s I-\tilde{A}| & =\left(s-s_{1}\right)\left(s-s_{2}\right)\left(s-s_{3}\right)\left(s-s_{4}\right) \\
& =(s-(-4+4 j))(s-(-4-4 j))(s-(-20))(s-(-20)) \\
& =s^{4}+48 s^{3}+752 s^{2}+4480 s+12800 \\
& =s^{4}+\alpha_{1} s^{3}+\alpha_{2} s^{2}+\alpha_{3} s+\alpha_{4} .
\end{aligned}
$$

Berdasarkan teorema Cayley-Hamilton, diperoleh

$$
\begin{aligned}
& \phi(\tilde{A})=\tilde{A}^{n}+\alpha_{1} \tilde{A}^{n-1}+\ldots+\alpha_{n-1} \tilde{A}+\alpha_{n} I=0, \\
& \phi(\tilde{A})=\tilde{A}^{4}+48 \tilde{A}^{3}+752 \tilde{A}^{2}+4480 \tilde{A}+12800 I=0 .
\end{aligned}
$$


40 Dian Puspita Bey

Selain itu,

$$
\begin{aligned}
\phi(A)= & A^{4}+48 A^{3}+752 A^{2}+4480 A+12800 I \\
= & {\left[\begin{array}{cccc}
0 & 1 & 0 & 0 \\
12.25 & 0 & 0 & 0 \\
0 & 0 & 0 & 1 \\
-2.45 & 0 & 0 & 0
\end{array}\right]+48\left[\begin{array}{cccc}
0 & 1 & 0 & 0 \\
12.25 & 0 & 0 & 0 \\
0 & 0 & 0 & 1 \\
-2.45 & 0 & 0 & 0
\end{array}\right] } \\
& +752\left[\begin{array}{cccc}
0 & 1 & 0 & 0 \\
12.25 & 0 & 0 & 0 \\
0 & 0 & 0 & 1 \\
-2.45 & 0 & 0 & 0
\end{array}\right]^{2}+4480\left[\begin{array}{cccc}
0 & 1 & 0 & 0 \\
12.25 & 0 & 0 & 0 \\
0 & 0 & 0 & 1 \\
-2.45 & 0 & 0 & 0
\end{array}\right] \\
& +12800\left[\begin{array}{cccc}
1 & 0 & 0 & 0 \\
0 & 1 & 0 & 0 \\
0 & 0 & 1 & 0 \\
0 & 0 & 0 & 1
\end{array}\right] \\
= & 10^{4}\left[\begin{array}{cccc}
2.2162 & 0.5068 & 0 & 0 \\
6.2083 & 2.2162 & 0 & 0 \\
-0.1872 & -0.0118 & 1.28 & 0.448 \\
-1.2417 & -0.1872 & 0 & 1.28
\end{array}\right] .
\end{aligned}
$$

Berdasarkan metode Ackermann diperoleh matriks feedback $K$ adalah

$$
\begin{aligned}
& K=\left[\begin{array}{llll}
0 & 0 & 0 & 1
\end{array}\right]\left[\begin{array}{llll}
B & A B & A^{2} B & A^{3} B
\end{array}\right]^{-1} \phi(A) \\
& K=\left[\begin{array}{lll}
0 & 0 & 0
\end{array}\right]\left[\begin{array}{cccc}
0 & 0.5 & 0 & 2.5 \\
0.5 & 0 & 2.5 & 0 \\
0 & -0.2041 & 0 & -0.2041 \\
-0.2041 & 0 & -0.2041 & 0
\end{array}\right] \\
& 10^{4}\left[\begin{array}{cccc}
2.2162 & 0.5068 & 0 & 0 \\
6.2083 & 2.2162 & 0 & 0 \\
-0.1872 & -0.0118 & 1.28 & 0.448 \\
-1.2417 & -0.1872 & 0 & 1.28
\end{array}\right] \\
& =10^{3}[-4.1407-1.0103-2.6122-0.9143] \text {. }
\end{aligned}
$$

Jadi dari penempatan pole yang diinginkan diperoleh matriks feedback $K$ yang dapat menstabilkan sistem pendulum terbalik. Sistem yang sudah stabil dapat dilihat pada Gambar 4.2.

\section{Ucapan Terima kasih}

Penulis mengucapkan terima kasih kepada Bapak Dr. Muhafzan, Ibu Arrival Rince Putri, M.T, M.Si, Bapak Dr. Admi Nazra, Bapak Dr. Dodi Devianto dan Bapak Narwen, M. Si yang telah memberikan masukan dan saran sehingga paper ini dapat diselesaikan dengan baik. 

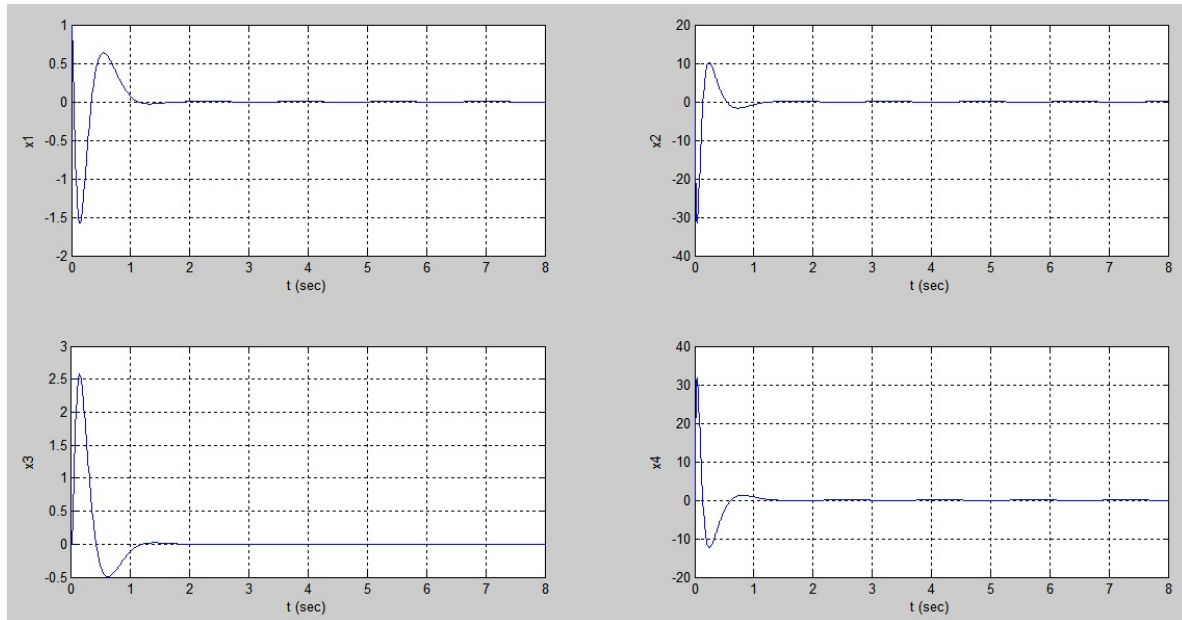

Gambar 4.2. Sistem Stabil

\section{Daftar Pustaka}

[1] Anton, H. 1991. Aljabar Linier Elementer Edisi Kedelapan-Jilid 1. Penerbit Erlangga, Jakarta

[2] Antsaklis, P. J, Michel, A. N. 2007. A Linear Systems Primer. Birkhauser, Boston, Basel, Berlin

[3] Heri, R. 2004. Penentuan kestabilan Sistem Kontrol Lup Tertutup Waktu Kontinu Dengan Metode Transformasi Kanonik Terkontrol. Jurnal Matematika dan Komputer

[4] Ogata, K. 1995. Discrete-Time Control Systems. Prentice-Hall, New Jersey

[5] Ogata, K. 2002. Modern Control Engineering, Fourth Editon. Prentice-Hall, New Jersey

[6] Prapanca, A dan Noor Anita, C. D. 2010. Simulasi Pendulum Terbalik (Inverted Pendulum) Pada Sebuah Kereta Menggunakan Bahasa Pemograman Matlab 7.5. Jurnal Penelitian Matematika dan Sains 